\title{
Complex synthesis yields breast-cancer therapy
}

\section{Drug approval marks culmination of a marathon trek from sea sponges to clinic.}

\section{BY HEIDI LEDFORD}

$\mathrm{T}$ he latest breast-cancer chemotherapy to hit the market is more than just a triumph for patients in desperate need of treatment. Approved by the US Food and Drug Administration on 15 November, the highly complex molecule Halaven (eribulin mesylate) is the product of nearly 25 years of struggle in the lab. It represents a hard-won victory for the total synthesis of natural products, a field of chemistry that, although still popular in academia, had gone out of fashion for many in the pharmaceutical industry.

Eribulin is a synthetic compound that mimics part of the structure of halichondrin $\mathrm{B}$, a molecule found in the sea sponge Halichondria okadai. Researchers learned that halichondrin B has potent tumour-fighting activity shortly after its discovery in 1986. But it is present in very low concentrations, making it difficult to isolate. The compound also has a fiendishly complicated structure - at the time of its discovery, producing it from scratch was well beyond the abilities of chemists.

A few years later, however, organic chemist Yoshito Kishi of Harvard University in Cambridge, Massachusetts, eyed the halichondrin B structure and decided to take a crack at it. His team had little interest in its anticancer properties, he says. They were simply looking for a project to test a chemical reaction - the Nozaki-Hiyama-Kishi reaction - that could be used to build bonds between carbon atoms.

Kishi's team had set themselves an enormous challenge with halichondrin B. Natural products often contain carbon stereocentres, in which surrounding atoms can be arranged in two mirror-image configurations. "If you don't get the stereocentres set up perfectly, it generates a mixture" of different molecules that can

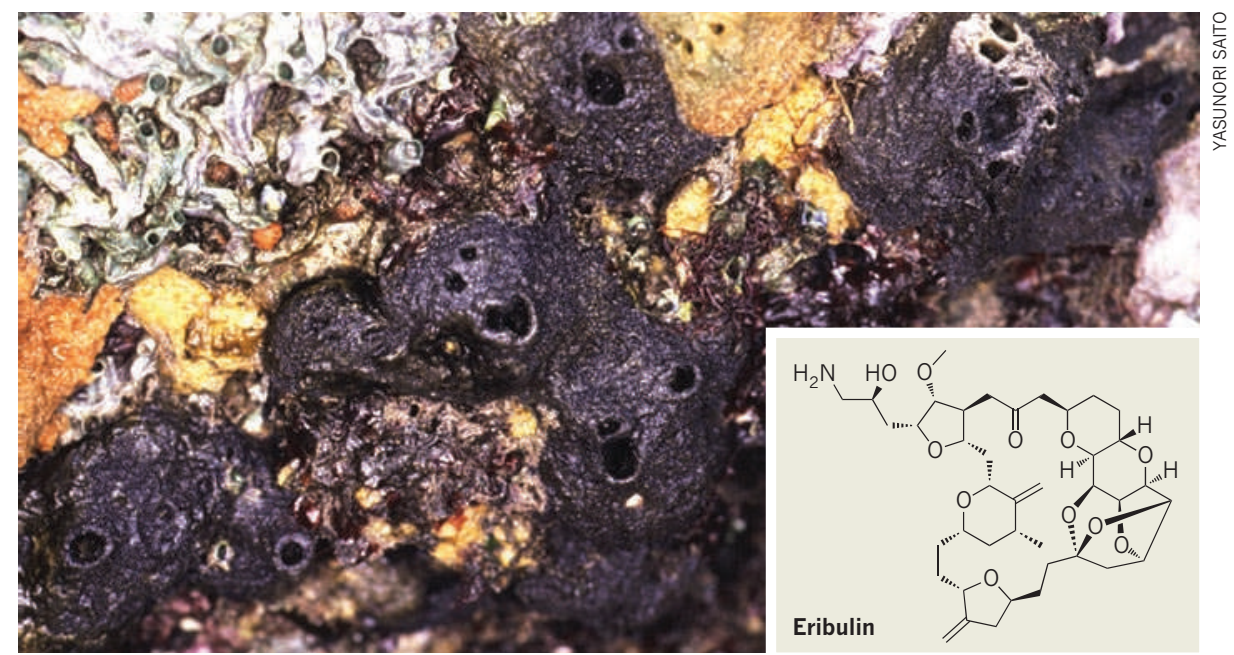

The drug eribulin (inset) was inspired by a compound from the sea sponge Halichondria okadai.

be extremely troublesome to separate, says Ian Paterson, a chemist at the University of Cambridge, UK, who works on natural-product synthesis. Although two mirror-image forms of a molecule are indistinguishable for most chemical reactions, they can produce completely different biological effects.

Halichondrin B has a staggering 32 stereocentres, meaning that there are $2^{32}-$ more than 4 billion - possible forms, or isomers, of the molecule. "It's just ridiculous," says Robert Salomon, an organic chemist at Case Western Reserve University in Cleveland, Ohio, whose lab spent four years unsuccessfully trying to synthesize the compound in the early 1990s.

Nevertheless, Kishi's team succeeded. By the time he published a method for synthesizing the compound in 1992 (T. D. Aicher et al. J. Am. Chem. Soc. 114, 3162-3164; 1992), researchers at the Natural Products Branch of the US National Cancer Institute (NCI) in Frederick, Maryland, had discovered that halichondrin B fights cancer cells by inhibiting a protein component of the cytoskeleton - the internal latticework of rods and filaments that gives a cell its shape. That protein, called tubulin, is needed to support the rapid growth of cancer cells and is the target of several other cancer chemotherapies, including Taxol (paclitaxel).

\section{DEEP-SEA DRUG}

But Kishi's synthesis was practical for generating only small quantities of halichondrin $\mathrm{B}$, unlikely to be enough to usher the compound through preclinical and then clinical testing, says David Newman, now chief of the NCI's Natural Products Branch. Newman decided that he would simply isolate the compound from natural samples. So he headed for the sea to hunt for the prized compound.

Newman and his team collected more than one tonne of Lissodendoryx, another type of

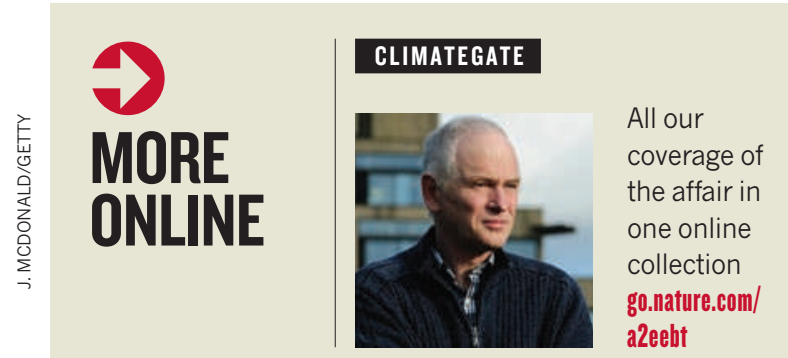

\section{LATEST NEWS}

Premature ageing reversed in mice go.nature.com/rxepdo

Cuts threaten UK archaeology go.nature.com/bzyt8a

Bespoke genetic circuits rewire human cells go.nature.com/s56pln

Protein factory mapped go.nature.com/nxngpd

\section{ON THE BLOG}

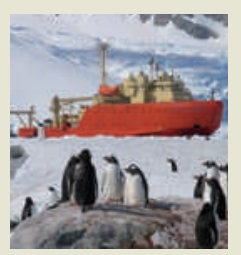

Reporter Jane Qiu's updates from a research vessel bound for the Antarctic Peninsula go.nature.com/wspgih 
sponge containing halichondrin $\mathrm{B}$, from the deep waters off New Zealand. He also teamed up with researchers to grow more of the sponges, flying seaplanes out to remote aquatic farms where the sponges grew attached to lines dangling 40 metres beneath buoys. The reward for his efforts: just 300 milligrams of halichondrin $\mathrm{B}$, the equivalent of a few grains of rice. "My hair turned white as a result of halichondrin B," he jokes.

Meanwhile, Tokyo's Eisai Pharmaceuticals had licensed the patent on Kishi's method and began synthesizing hundreds of analogues of the compound. Newman's haul from New Zealand was just enough to conduct comparative studies with some of these analogues. One of them, eribulin, is more potent than halichondrin $B$ yet also substantially smaller and easier to make. But it still has 19 stereocentres (see structure, inset), and production of eribulin on a commercial scale seemed unfathomable.

Eisai says that eribulin takes 62 steps to synthesize - a remarkably long process for a marketable drug. The company was initially apprehensive about the project, says Kishi. But once the phase I study results had shown that the drug was safe - and revealed hints of clinical efficacy - "all the reservations disappeared”, he says.

Further clinical trials showed that eribulin extends the lifespan of patients with late-stage breast cancer by an average of 2.5 months in those who are not benefiting from other chemotherapies such as Taxol, also a natural-product derivative. Analysts suggest that eribulin could command a US\$1-billion market if it is approved for treatment of other cancers.

Few other pharmaceutical companies have been willing to bet on complex natural products. During the 1990s, many largely abandoned natural-product chemistry, focusing more on screening large libraries of synthetic chemicals for drug candidates, says Michael Jirousek, who once worked on halichondrin B synthesis and is now chief scientific officer and co-founder of Catabasis, a biotechnology company in Cambridge, Massachusetts. "Screening natural products and isolating the active ingredients is becoming a lost art," he says.

Proponents of total synthesis point to eribulin as proof that their approach, albeit arduous, can be highly successful. Phil Baran, a synthetic chemist at the Scripps Research Institute in La Jolla, California, says that more young investigators are entering the field and that improvements in chemical techniques are making it possible to synthesize additional complex molecules by commercially viable routes. "As advances in organic chemistry become greater and greater," he says, "I think we're going to see a lot more complex compounds being pursued by companies." -

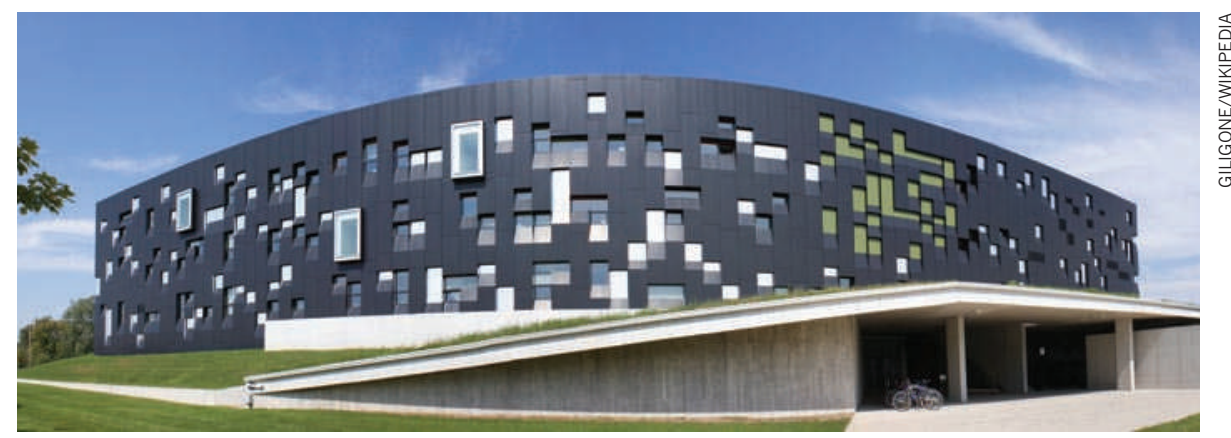

Canada's Perimeter Institute boasts a freewheeling intellectual environment — and a gourmet bistro.

RESEARCH

\section{Physics centre plans rapid growth}

Perimeter Institute steps up drive to attract top talent.

\section{BY IVAN SEMENIUK}

$\mathrm{N}$ ewton, Maxwell, Einstein, Bohr, Dirac - the list reads like the ultimate physics dream team. That the Perimeter Institute for Theoretical Physics in Waterloo, Canada, has chosen to name five new research chairs after some of the greatest physicists in history is a sign of its lofty aspirations.

"We're scouring the world for exceptional talent," says director Neil Turok, who took the helm at the Perimeter in 2008. The institute began attracting up-and-coming researchers soon after its creation, but it has had a harder time building into its ranks the experience and scientific prowess to rival more established theoretical centres, such as the Institute for Advanced Study (IAS) in Princeton, New Jersey. The new chairs, announced on 29 November, are designed to attract top theorists in "a gathering of critical mass around the most fundamental questions", Turok says. "Our mission is to make breakthroughs."

This is not the first time a physics institute has announced such an ambitious goal, but the Perimeter's resources give it a better chance than most of achieving it. The institute was founded in 1999 with a hefty personal gift from entrepreneur Mike Lazaridis, whose company, Research in Motion, makes the popular BlackBerry products, and it has grown quickly since then through additional public and private funds.

The faculty now numbers 14 full-time posts and 12 part-time associate posts, with more hirings expected in 2011. Largely spared the commitments that come with an academic appointment at a university, researchers at the Perimeter enjoy an unfettered and freewheeling intellectual environment, together with less cerebral indulgences, including a gourmet bistro and a squash court. The institute has begun to make significant contributions in areas such as quantum field theory.

"The chair holders will be free to engage in investigator-driven research, without limits or mandates," according to a description of the new positions. An Can\$8-million (US\$7.8-million) endowment has been secured for the first chair, named after Isaac Newton, with half the money provided by the Perimeter's existing endowment and the rest by BMO Financial Group, one of Canada's largest banks. The institute is now seeking partners to fund the remaining chairs.

"The place is really flourishing now," says Nima Arkani-Hamed, a theoretical physicist at the IAS. Despite initial reservations when the Perimeter first opened, Arkani-Hamed now collaborates frequently with colleagues there and has seen growing numbers of IAS students and postdocs choosing job offers from the Perimeter over those from more established institutions. IAS researcher Davide Gaiotto, who will take up a faculty position at the Perimeter next year, agrees that there is no shortage of physics talent to fill the new positions. Others say that privately endowed institutions such as the Perimeter and the Simons Center for Geometry and Physics at Stony Brook University, New York, are helping to keep theoretical physics active while the economic downturn hits public universities in the United States and Europe.

Even a few strategic hirings can have a powerful effect on a field, notes Michael Douglas, a string theorist at the Simons Center. Douglas recalls his time as a postdoc at Rutgers University in Piscataway, New Jersey, when four key faculty appointments in 1989 - the 'string quartet' - led to a collaboration that transformed string theory. "If you choose right," he says, "then things can really take off." 